\title{
Gurias na Computação: fortalecendo e incentivando a participação feminina no Ensino Superior
}

\author{
Isadora Garcia Ferrão, Aline Vieira de Mello, Amanda Meincke Melo \\ Universidade Federal do Pampa (Unipampa) - Campus Alegrete Av. Tiarajú, 810 - \\ Ibirapuitã - 97.546-550 - Alegrete - RS - Brasil \\ isadora-gf@hotmail.com, \{alinemello, amanda.melo\}@unipampa.edu.br
}

\begin{abstract}
In the context of publicizing and encouraging the women's participation in TI area, this work reports initiatives of the Gurias in Computing extension activity. Targeted at girls who are in basic education and students of undergraduate computer programs, this activity organizes a series of actions, including meetings, the production of a game, the dissemination of undergraduate programs, among others. In this way, Gurias in Computing has given visibility to women's participation in computing and contributed to the strengthening of links between students of undergraduate computer programs.
\end{abstract}

Resumo. No contexto de divulgação e incentivo à participação de mulheres na área de TI, este trabalho relata iniciativas da atividade de extensão universitária Gurias na Computação. Voltada a meninas que estão na Educação Básica e a graduandas de cursos na área da Computação, essa atividade organiza uma série de ações, incluindo encontros, a produção de um jogo, a divulgação dos cursos de graduação, entre outras. Dessa forma, tem se dado visibilidade à participação das mulheres na Computação e contribuido ao fortalecimento de vínculos entre acadêmicas dos cursos da área.

\section{Introdução}

Embora vários nomes femininos tenham feito contribuições significativas na área de Tecnologia da Informação (TI), há pouca visibilidade de modelos femininos. A exclusão de mulheres em ambientes profissionais e estudantis, a falta de incentivo para seguirem carreira nas exatas e a cultura masculina criada na Computação são alguns fatores citados para a área ter menos mulheres ao longo dos anos [Burge e Suarez 2005; Beaubouef e Zhang 2011]. Nesse contexto, ações têm sido desenvolvidas para incentivar a participação feminina na área, a exemplo do programa Meninas Digitais, da Sociedade Brasileira de Computação (SBC) [CSBC 2011].

Deste modo, levando em conta a necessidade de ser debatida inserção da mulher na Computação e o desconforto de acadêmicas dos cursos Ciência da Computação e Engenharia de Software da Unipampa com a realidade apresentada, organizou-se o Fórum Gurias na Computação [Ferrão e Melo 2016]. A amplitude de assuntos e possibilidades identificadas durante as edições do Fórum, impulsionou a organização 
atividade Gurias na Computação, cujo objetivo é promover ações que ampliem a participação feminina na área da Computação. A atividade Gurias na Computação está vinculada ao programa de extensão Programa C - Comunidade, Computação, Cultura, Comunicação, Ciência, Cidadania, Criatividade, Colaboração [Mello e Melo 2017] e tem sido um importante espaço para discutir assuntos relacionados às questões de gênero na área da Computação.

As ações da Gurias na Computação têm como público alvo alunas de escolas da Educação Básica (Ensino Fundamental e Médio) e graduandas dos cursos da área da Computação do município. As ações voltadas às alunas da Educação Básica têm como objetivo apresentar a área da Computação como uma possibilidade para que elas desenvolvam suas carreiras profissionais e, desta forma, ampliar o ingresso de meninas nos cursos da área. Já as ações voltadas para as graduandas têm como objetivo reduzir a evasão dos cursos de Computação, ampliando, assim, a participação feminina no mercado de trabalho da área de TI e também na academia.

Este artigo tem o objetivo de apresentar a atividade Gurias na Computação, as ações desenvolvidas até o momento, os resultados obtidos, os desafios encontrados e as perspectivas futuras. O restante deste texto está organizado como segue. A metodologia adotada para a organização, execução e avaliação das ações é descrita na seção 2. A seção 3 apresenta os resultados obtidos. Por fim, as considerações finais e perspectivas futuras são apresentadas na seção 4.

\section{Metodologia}

A equipe executora da Gurias na Computação é composta por sete discentes e três docentes dos cursos de Ciência da Computação e Engenharia de Software da Unipampa, a maioria do gênero feminino e todos voluntários. Além disso, discentes e docentes do curso de Análise e Desenvolvimento de Sistemas do Instituto Federal Farroupilha Campus Alegrete são parceiros nas ações desenvolvidas.

A equipe executora do Gurias na Computação realiza reuniões periódicas, nas quais são discutidas e organizadas, de forma colaborativa, as ações a serem executadas. Parte do trabalho desenvolvido pelos extensionistas é realizado a distância com o apoio de ferramentas gratuitas que facilitam a organização, a comunicação, a colaboração e o compartilhamento de ideias e de artefatos. Suas ações são avaliadas por todos os envolvidos - participantes e membros da equipe executora.

A comunicação da Gurias na Computação com a comunidade é realizada, na maioria das vezes, através da página em uma rede social e por compartilhamentos de suas publicações nessa rede. Os membros da comunidade podem assumir diferentes papéis nas ações de extensão, como: ouvintes, partes interessadas, coautores, palestrantes e avaliadores.

O Quadro 1 sumariza as ações desenvolvidas desde a criação da atividade Gurias na Computação, em março de 2016, bem como seu público alvo. 
Quadro 1. Ações da Gurias na Computação realizadas até março de 2017.

\begin{tabular}{|c|c|c|}
\hline Ação & Data & Público-alvo \\
\hline $\begin{array}{c}\text { Criação da página Gurias } \\
\text { na Computação }\end{array}$ & 06 de junho de 2016 & comunidade \\
\hline $\begin{array}{c}\text { I Encontro Gurias na } \\
\text { Computação }\end{array}$ & 25 de junho de 2016 & $\begin{array}{c}\text { graduandos dos cursos da área } \\
\text { de Computação do município }\end{array}$ \\
\hline $\begin{array}{c}\text { Divulgação do perfil de } \\
\text { mulheres de destaque na } \\
\text { área da Computação }\end{array}$ & $\begin{array}{c}\text { julho a dezembro de } \\
2016\end{array}$ & comidade \\
\hline $\begin{array}{c}\text { Participação de mulheres } \\
\text { em ações de divulgação dos } \\
\text { cursos de Computação }\end{array}$ & contuo educação básica \\
\hline $\begin{array}{c}\text { II Encontro Gurias na } \\
\text { Computação }\end{array}$ & 12 de outubro de 2016 & $\begin{array}{c}\text { graduandos dos cursos da área } \\
\text { de Computação do município }\end{array}$ \\
\hline $\begin{array}{c}\text { Projeto Codificar } \\
\text { novembro e } \\
\text { dezembro de } 2016\end{array}$ & $\begin{array}{c}\text { alunos do ensino médio do } \\
\text { muniópio }\end{array}$ \\
\hline $\begin{array}{c}\text { Apresentação de trabalhos } \\
\text { no SIEPE }\end{array}$ & $\begin{array}{c}22 \text { a } 24 \text { de novembro } \\
\text { de } 2016\end{array}$ & $\begin{array}{c}\text { graduandos de diferentes } \\
\text { cursos da região }\end{array}$ \\
\hline $\begin{array}{c}\text { Painel em alusão ao dia } \\
\text { Internacional da Mulher }\end{array}$ & 08 de março de 2017 & $\begin{array}{c}\text { comunidade acadêmica da } \\
\text { universidade }\end{array}$ \\
\hline
\end{tabular}

\section{Resultados}

Durante o I Encontro Gurias na Computação, com o tema "O Protagonismo Feminino" [Lopes, Ferrão e Mello 2016], compartilharam-se perfis de mulheres que atuam na Computação e os participantes se divertiram e aprenderam com o jogo de tabuleiro Mulheres na Computação, composto por um conjunto de perguntas elaborado com base no perfil de mulheres de destaque na história da área [Lopes et al. 2016]. O encontro originou a divulgação periódica do perfil de mulheres de destaque na área da Computação na página Gurias na Computação, na rede social Facebook. Assim, tem-se a expectativa que um número maior de pessoas perceba que muitas mulheres contribuíram e continuam a contribuir para o avanço da Computação no Brasil e no mundo.

O envolvimento de meninas na divulgação dos cursos da área da Computação a estudantes da educação básica do município (ex.: Feira do Livro, Feira de Ciências da EEEF Arthur Hormain) tem mostrado, através do exemplo, que a Computação também é lugar de mulheres. Destaca-se o projeto Codificar, em parceria com o Instituto Federal Farroupilha. Além de envolver meninas do Ensino Médio em atividades de programação para dispositivos móveis, o projeto apresenta em sua equipe executora mulheres de ambas as instituições - entre elas, professoras e alunas.

O II Encontro Gurias na Computação trouxe para o debate o Feminismo, contando com a colaboração de uma professora da Educação Básica do município, que tem estudado e debatido o tema. Clarificou-se, assim, o papel do Feminismo e a sua inter-relação com a inserção da mulher na área de TI. Além disso, acadêmicas da área 
da Computação, em fase final de desenvolvimento do curso, compartilharam suas experiências durante a graduação. Esse momento foi bastante significativo, ao proporcionar a valorização de graduandas na área e a identificação dos ouvintes com as experiências apresentadas, incentivando a continuidade dos estudos de graduação.

Mais recentemente, a atividade Gurias na Computação contribuiu à organização de um painel em alusão ao Dia Internacional da Mulher. Além de valorizar as mulheres num Campus com a presença majoritariamente masculina, o painel homenageou a professora Márcia Cera (in memorian), uma das Gurias na Computação que nos deixou precocemente.

\section{Considerações Finais}

A Gurias na Computação tem proporcionado às acadêmicas dos cursos de Computação do município espaços de escuta e trocas de experiências, fortalecendo-as em sua formação na área da Computação. Além disso, tem incentivado a participação das acadêmicas nas ações que divulgam a área a meninas da Educação Básica, que podem tê-las como modelo e referência, passando a reconhecer os cursos da área da Computação como alternativa de formação profissional.

Algumas ações já foram desenvolvidas voltadas tanto à comunidade interna quanto externa à Universidade. Nas ações voltadas à comunidade interna, pretende-se ampliar o número de participantes, inclusive do gênero masculino, visto que questões de gênero devem ter o envolvimento de todos. Quanto às ações voltadas à comunidade externa, busca-se ampliar a relação com a Educação Básica, por exemplo, pela participação em Feiras das Profissões das Escolas e divulgação do jogo Gurias na Computação em versão digital.

\section{Referências}

Beaubouef, T., Zhang, W. (2011) "Where are the women computer science students?", In: Journal of Computing Sciences in Colleges, v. 26, n. 4, p. 14-20.

Burge, J., Suarez, T. (2005), "Preliminary Analysis of Factors Affecting Women and African Americans in the Computing Sciences, TAPIA'05.

CSBC, "Fórum Meninas Digitais", http://www.dimap.ufrn.br/csbc2011/eventos/wit.php, 2011.

Ferrão, I., Melo, A. (2016), "I Fórum Gurias na Computação: relato de experiências e desdobramentos", CSBC 2016.

Lopes, G., Ferrão, I., Mello, A. (2016), "I Encontro Gurias na Computação: O Protagonismo Feminino", SIEPE 2016.

Lopes, G., Santos, P., Oliveira, A., Mello, A. (2016), "Jogo Mulheres na Computação: uma Forma de Divulgar o Protagonismo Feminino”, SIEPE 2016.

Mello, A.; Melo, A. (2017) "Programa C - Comunidade, Computação, Cultura, Comunicação, Ciência, Cidadania, Criatividade, Colaboração", Interações dialógicas: ações extensionistas das engenharias e da computação com a sociedade, C. Tolfo, Bagé, Ediurcamp, p. 11-30. 